\title{
THE CONTRIBUTION OF ROMANIA TO CLIMATE CHANGE - THE EFFECTS OF ACCOUNTING THE GHG EMISSIONS FROM LAND USE, LAND-USE CHANGE AND FORESTRY $($ LULUCF)
}

\section{Ramona Zgavarogea ${ }^{1}$, Mihaela Iordache ${ }^{\mathbf{1}^{*}}$, Andreea Maria Iordache ${ }^{1}$, Marius Constantinescu ${ }^{1}$, Felicia Bucura ${ }^{1}$, Roxana Elena Ionete ${ }^{1}$, Remus Grigorescu ${ }^{2}$, Constantin Nechita ${ }^{3 *}$}

\author{
${ }^{I}$ National Research and Development Institute for Cryogenics and Isotopic Technologies - ICSI Rm. \\ Valcea, 4 Uzinei Street, P.O. Box Râureni 7, 240050, Rm. Valcea, Romania \\ ${ }^{2}$ Constantin Brancoveanu University, Bulevardul Nicolae Bălcescu 39, 240177, Râmnicu Vâlcea, Romania \\ ${ }^{3}$ National Research and Development Institute for Forestry "Marin Drăcea" Calea Bucovinei, 73 bis, \\ 725100, Câmpulung Moldovenesc, Romania
}

\begin{abstract}
:
This study aimed to analyze Romanian (RO) involvement in the LULUCF sector by considering the Intergovernmental Panel on Climate Change (IPCC) good practice guidance (GPG). Trends were assessed using the Mann-Kendall (MK) test for trend estimation to determine the total greenhouse gas (GHG) (GHGCO${ }_{2}$-eq.) emissions/ removals. The results emphasized the increasing average annual levels of emissions/removals in both the EU-28 and RO when the subperiods from 1990-2005 and 2005-2017 were analyzed. Kendall's analysis of GHG removal showed a positive trend in Romanian GHG removals, and no trend was observed for the EU-28. In comparison, the emissions indicated an increasing trend for RO and a decreasing trend for the EU-28. The $\mathrm{GHGCO}_{2}$-eq. generated by the LULUCF sector decreased to an average annual rate of $0.5 \%$ per year in the EU-28. In Romania, these emissions increased by approximately $0.2 \%$ per year on average. Between 1990 and 2017, the $\mathrm{CO}_{2}$ total absorption increased to $0.9 \%$ per year. The methane absorption also increased by $11.7 \%$ per year, and no significant increasing trend was observed for methane. The dynamics of $\mathrm{GHGCO}_{2}$-eq. emissions/removals in RO and LULUCF sectors showed that settlement had decreased in wetlands, and settlement of other land areas had increased. Assessing GHG gas emissions is essential for allowing each sector to promote specific strategies, policies and action plans. This will improve the national-level monitoring of the LULUCF sector and make this information more accessible to decision makers by raising awareness of the Romanian position within the EU-28.
\end{abstract}

\section{Article info:}

Received 14 January 2021

Received in revised form

26 February 2021

Accepted 14 March 2021

Available online 16 April 2021

Keywords:

Greenhouse gases, Land use, Landuse change, Forestry, Mitigation

Climate change

*Corresponding authors: Constantin Nechita, E-mail: nechitadendro@gmail.com, and Mihaela Iordache, E-mail: mihaela.iordache@icsi.ro 
How to cite: Zgavarogea, R., Iordache, M., Iordache, A. M., Constantinescu, M., Bucura, F., Ionete, R. E., Grigorescu, R., Nechita, C., (2021). The contribution of Romania to climate change - the effects of accounting the GHG emissions from LULUCF. Smart Energy and Sustainable Environment, 24(1), 5-20, https://DOI: org/10.46390/j.smensuen.24121.433

\section{BACKGROUND}

Land use, land-use change and forestry can act as sources of atmospheric emissions and as emission sinks through the removals of atmospheric $\mathrm{CO}_{2}$. The balance of atmospheric emissions and removal of emissions is the net emissions/removals in the LULUCF sector. The main objective of the United Nations Framework Convention on Climate Change (UNFCCC) was to "stabilize global greenhouse gas (GHG) concentrations in the atmosphere at a level that would prevent dangerous anthropogenic interference with the climate system" (Ellison et al., 2011; UNFCCC, 1992).

Under the Kyoto Protocol, EU member states committed themselves to guarantee the offset of an equivalent amount of $\mathrm{CO}_{2}$ to the quantity of greenhouse gas emissions from land use until 2020, which has been made possible by further action in this sector. The European Commission aims to enshrine this principle (the so-called "free flow rule") in EU law between 2021 and 2030 by incorporating land use and forestry into EU emissions reduction efforts (Benndorf et al., 2007; Vauhkonen and Packalen, 2018). Forest owners and farmers' actions for ensuring carbon storage in forests and soils will, therefore, contribute to the EU's commitment under the Paris Agreement on Climate Change to reduce greenhouse gas emissions by at least $40 \%$ compared to 1990 levels by 2030 (UNFCCC, 2015; Forsell et al., 2019).

The United Nations Framework Convention on Climate Change will remain in effect after 2020. In contrast, the mandate of the Kyoto Protocol ends in 2020, which is the final year of the second commitment period agreed upon in Doha in 2012. The Paris Agreement ensured a continued commitment by the involved parties after 2020 and the cohesion of the Kyoto Protocol for those countries that had KP targets. Decision 1/CP1 puts the agreement into effect and sets out the principles for the action on various processes and work programs that will run in the future with respect to the parties' involvement in climate change mitigation after 2020 (European_Commission, 2016; Fragkos et al., 2017).

The successful integration of LULUCF into EU-28 climate policy and carbon-trading frameworks assists emerging international climate change mitigation efforts. The UNFCCC subsidiary body for scientific and technological advice (SBSTA) has invited parties and admitted observer organizations to submit views on issues related to "a more comprehensive accounting of anthropogenic emissions by sources and removal by sinks from land use, landuse change and forestry (LULUCF), including through a more inclusive activity- or landbased approach" (Ellison et al., 2014). The role of LULUCF and agriculture, and their potential contributions through the sequestration of carbon, could become decisive for achieving equivalent emissions and removals. First, both LULUCF and agriculture can contribute through a reduction of emissions caused by land-use change, e.g., deforestation or drainage of wetlands, which would contribute to an overall decrease in emissions. Second, carbon can be sequestered in growing biomass (e.g., forest growth, afforestation, restoration of degraded land). However, it must be noted that maintaining the continued additional sequestration of carbon over time becomes difficult due to saturation, and reductions are needed as well (European_Commission, 2016).

The reduction of GHG emissions requires action from domestic industries, energy, and several other sectors (Miricioiu et al., 2016a; Miricioiu et al., 2016b). The promotion of new techniques in land use, land-use change and forestry activities enhances the potential of carbon sinks. Moreover, clean development mechanisms, emission trading schemes and joint implementation among Annex I countries (UNFCCC, 2015) could use the carbon sinks 
produced by afforestation, reforestation, forest management, cropland management, grazing land management and revegetation activities. All targets were carried out in the non-Annex I countries after 1990, as was stipulated in the accounting rules of the carbon sources/sinks produced by LULUCF activities in the first commitment period to complete the emission reduction targets. The Annex I countries could use the carbon sinks provided by LULUCF activities to decrease the pressure to reduce their emissions during the first commitment period (Liu et al., 2011; Pichancourt et al., 2018).

The complexities inherent in LULUCF activities led to contentious and prolonged debates about the merits of their inclusion in the first commitment period of the Kyoto Protocol (2008-2012). However, the integration of these activities played a crucial role in the agreement on the general framework of the Kyoto Protocol. In this context, the LULUCF will likely continue to play a substantial role in negotiations on national commitments post-2012 (Höhne et al., 2007; Schlamadinger et al., 2007; Regulation 842, 2018). Through adherence to the objectives of the UNFCCC and the incorporation of several critical features, a future framework can more effectively address the mitigation challenges and opportunities.

Climate change has become an important global issue that is related to energy, economics, the environment, and technology. Without further action to reduce global GHG emissions, global warming is likely to exceed $2{ }^{\circ} \mathrm{C}$ above the pre-industrialization levels (UNFCCC, 2015). Such development would have a considerable impact on the global landscape and sea levels and affect the economic and social development of countries around the globe. Accordingly, it is necessary to identify the paths for GHG emission management in the major emitting countries, which are subject to international commitments and national policies (Jung, 2005; Kissinger et al., 2019; Zheng et al., 2019).

LULUCF activities can reduce GHG emissions and remove atmospheric GHGs by changing management practices for forests, cropland and grazing lands. Efforts in this sector have been seen as the most cost-effective way to stabilize global atmospheric $\mathrm{CO}_{2}$ concentrations and to reduce global warming (Liu et al., 2016). The agriculture, forestry and other land use (AFOLU) sector plays a predominant role in GHG emissions/carbon sequestration in many developing countries. However, the AFOLU is reported to contribute only approximately one-fourth of the total GHG emissions at the global level (Pradhan et al., 2017; Meehan et al., 2019).

LULUCF emphasize several categories of land, with the most significant contributions being "forestland remaining forestland", "land conversion to forestland" and "cropland remaining cropland". The most important sources of emissions are represented by "conversion to other lands (a category of lands not included in other categories of use, namely, the new islands on the Danube, the sand lenses, the decrease of forestland due to logging, etc.)" and "lands converted to human settlements", which included forest conversions. The amount of $\mathrm{CO}_{2}$ absorbed annually by forest vegetation land was relatively constant over time, and the annual quantities of greenhouse gas emissions (other than $\mathrm{CO}_{2}$, $\mathrm{N}_{2} \mathrm{O}$ and $\mathrm{CH}_{4}$, respectively) from the burning of biomass showed a very low incidence of forest fires (IPCC, 2006). The category of "land converted to forestland" contributes significantly in the LULUCF sector and includes both forests resulting from planting (directly induced by anthropogenic action) and those resulting from the natural extension of forest vegetation (actions that are not consequences of direct anthropogenic action but rather are indirect effects).

Land use, land-use change, and forestry currently contribute approximately $10 \%$ of the global greenhouse gas emissions of $\mathrm{CO}_{2}$ and approximately $25 \%$ of those of $\mathrm{CH}_{4}$ and $\mathrm{N}_{2} \mathrm{O}$ but contribute $35 \%$ of the total accumulated anthropogenic GHG emissions. Approximately 
$33 \%$ of current anthropogenic emissions are removed by terrestrial ecosystems, mostly forests (Munawar et al., 2015; Keith et al., 2019).

Forests and active agricultural land play an essential role in the fight against climate change. Trees and plants absorb and store carbon dioxide, removing it from the atmosphere. In general, it is estimated that in the EU-28, the activities to remove carbon from the atmosphere remove quantities equivalent to approximately $9 \%$ of the total greenhouse gas emissions generated by other sectors. On the other hand, certain agricultural activities, such as forestry and agricultural exploitation of wetland drainage and pasture plowing, reduces carbon uptake or even reverses it and can turn forests and agriculture into emission sources (Berglund and Berglund, 2010). Agriculture, which contributes approximately 10\%-12\% of the total global anthropogenic GHG emissions, is recognized as a critical source of greenhouse emissions. The $\mathrm{CO}_{2}$ and $\mathrm{CH}_{4}$ emissions from cropland are due to a variety of practices in the agricultural sector, including soil tillage, soil drainage, rice management, biomass burning, flooding, and the use of fertilizers and residue. $\mathrm{N}_{2} \mathrm{O}$ warms the atmosphere 298 times more strongly than $\mathrm{CO}_{2}$ (with 20 years distant time in the future). The hundredyear time horizon derived from soil microorganism activities (nitrification and denitrification processes) can be reduced due to no-tillage field management practices (Yan et al., 2017; Pradhan et al., 2017; Li et al., 2018).

In Europe, a regulation on land use, land-use change and forestry was adopted in the climate and energy framework for 2030 (Regulation 841, 2018). The regulation introduces an updated system of accounting rules, which was previously regulated by Decision No. 529/2013/EU and by the Kyoto Protocol, as well as flexible mechanisms for transferring emissions and removals with the Effort-Sharing Regulation. LULUCF regulation is the third pillar of the European climate and energy framework 2030. Together with the Effort Sharing Regulation and the revised ETS Directive, the framework creates a mandatory legal basis for EU-28 efforts to reduce global greenhouse gas emissions by at least $40 \%$ compared to 1990 levels by 2030 .

Following the Paris Agreement, the international community has committed to upgrading to a low-carbon economy. Different countries are currently implementing policies to facilitate the shift to cleaner economies. The commission presented a Communication on the implementation of the commitments made under the Paris Agreement in March 2016, which was followed by a European strategy for a move to low emissions in June 2016 (UNFCCC, 2015; Kuramochi et al., 2017; Moe and Røttereng, 2018).

The strategy for a move to low emissions outlined several concrete measures to help Europe remain competitive and be able to meet the increasing mobility needs of people and goods. The strategy for moving to low emissions, which contributes to achieving the goals of the Energy Union, established transparent and equitable guiding principles that allow member states to prepare for the future.

\section{METHODOLOGY}

\subsection{Data sources}

According to the UNFCCC protocol, several countries need to report their GHG emission inventories yearly. The net and sector-specific yearly $\mathrm{GHG}_{\mathrm{CO}_{2} \text {-eq. }}\left(\mathrm{CO}_{2}, \mathrm{CH}_{4}, \mathrm{~N}_{2} \mathrm{O}\right)$ emission data, which were reported as megatons $\mathrm{CO}_{2}$-eq./year, were investigated for the period from 1990-2017. A broad similar data set was included from the European Environment Agency (EEA), the National Institute of Statistics (NIS Romania) and the national greenhouse gas inventory. According to the Annex I countries and the following six sectors, energy, industrial processes, agriculture, land use/land-use change and forestry, 
waste and transport sector, were included according to the 2006 IPCC guidelines for national GHG inventories. The principles of measurement, reporting and verification (MRV) were used to establish biennial update reports (BURs), public communication and methodologies associated with the revised 1996 IPCC guidelines for national greenhouse gas inventories incorporated in decision 17/CP.8.

The Mann-Kendall (MK) trend test, which is a nonparametric statistical analysis (Kendall, 1948), was used to identify the long-term trends in greenhouse gas emissions between 1990 and 2017. The negative and positive signs estimated the upward and downward direction of the trend in the analyzed data. The two-tailed test for the null hypothesis $\left(\mathrm{H}_{0}-\right.$ the presence of no significant trend $)$ and the alternative hypothesis $\left(\mathrm{H}_{\mathrm{A}}-\right.$ the presence of a significant increasing or decreasing trend) were conducted. The null hypothesis was rejected, and $\mathrm{H}_{\mathrm{A}}$ was adopted if the $\mathrm{p}$-value $<0.05$.

\section{RESULTS AND DISCUSSION}

\subsection{Trends in GHG emissions / removals from the LULUCF sector in the EU-28 member states}

The land use classification according to the 2006 IPCC guidelines (IPCC, 2006) defined six main categories of land use: forestland, cropland, grassland, wetlands, settlements, and other areas and conversions between them. In the EU-28, the net removal in the LULUCF sector increased before 2005 to approximately 286.3 million tons of $\mathrm{CO}_{2}$ equivalent $\left(\mathrm{CO}_{2}\right.$-eq.). After 2005, 301.3 million tons of $\mathrm{CO}_{2}$-eq./year were calculated; in the period from 1990-2017, the average annual net amount absorbed was 292.5 million tons of $\mathrm{CO}_{2}$-eq./year (Table 1).

Table 1. Synthetic comparative indicators of the evolution of the net removal during the period 1990-2017

\begin{tabular}{|c|c|c|c|c|c|c|}
\hline \multirow{2}{*}{ Time } & \multicolumn{2}{|c|}{$\begin{array}{c}\text { The average annual } \\
\text { level, thousand tons } \\
\text { CO }_{2} \text {-eq/year }\end{array}$} & \multicolumn{2}{|c|}{$\begin{array}{c}\text { The absolute average } \\
\text { change, thousand } \\
\text { tons CO }\end{array}$} & \multicolumn{2}{|c|}{$\begin{array}{c}\text { Rate average } \\
\text { annual } \\
\text { \% }\end{array}$} \\
\cline { 2 - 7 } & EU-28 & RO & EU-28 & RO & EU-28 & RO \\
\hline $\mathbf{1 9 9 0 - 2 0 0 5}$ & 286,317 & 20,157 & 4,204 & 166 & $1.5 \%$ & $0.7 \%$ \\
\hline $\mathbf{2 0 0 5 - 2 0 1 7}$ & 301,276 & 20,967 & $-4,163$ & 64 & $-8.5 \%$ & $0.3 \%$ \\
\hline $\mathbf{1 9 9 0 - 2 0 1 7}$ & 292,487 & 20,507 & 485 & 102 & $0.2 \%$ & $0.5 \%$ \\
\hline
\end{tabular}

In Romania, the average yearly level of removal in the LULUCF sector were approximately 20.2 million tons of $\mathrm{CO}_{2}$-eq./year during the 1990-2005 period (Fig. 1a). After 2005, the average annual level increased to approximately 21.0 million tons $\mathrm{CO}_{2}-$ eq./year. In Romania, the net elimination, multiplied by 166 thousand tons of $\mathrm{CO}_{2-}$ equivalent, compared to the EU-28, in the period 1990-2005. The 2005-2017 period was observed to decrease to 64 thousand tons of $\mathrm{CO}_{2}$-eq./year. We noted that the average annual levels in the EU-28 increased by $5.2 \%$ in the $2005-2017$ period compared to an increase of only $4 \%$ in the $1990-2005$ period in Romania. Additionally, Romania's contribution was just over one-fifth of the average annual increase in the net removal recorded at the EU-28 level. For the analyzed period (1999-2017), 102 thousand tons $\mathrm{CO}_{2^{-}}$ eq./year compared to the average yearly growth recorded at the EU-28 level, 485 thousand tons $\mathrm{CO}_{2}$-eq./year (Fig. 1). 
The trend analysis highlighted that the $\mathrm{RO} \mathrm{CO}_{2}$-eq. removal had a Kendall's tau value of 0.48 ( $p$-value $<0.0002$ ) in comparison to EU-28, where Kendall's tau $=0.06$ and the $\mathrm{p}$-value $=0.65$. The risk of rejecting the hypothesis that no trend in the time-series $\mathrm{RO}$ $\mathrm{CO}_{2}$-eq. removal analyzed was lower than $0.02 \%$, and for EU-28 $\mathrm{CO}_{2}$-eq. removal, it is true for $65.29 \%$. On the other hand, for the $\mathrm{RO}$ emissions, $\mathrm{CO}_{2}$-eq. was calculated using a Kendall's tau value of 0.92 (p-value $<0.0001$ ), and for the EU-28 emissions, the Kendall's tau value for the $\mathrm{CO}_{2}$-eq. was -0.60 (p-value <0.0001) (Fig. 1b). In both cases, the risk of rejecting the null hypothesis was lower than $0.01 \%$, indicating an increasing trend for Romania and a decreasing trend for the EU-28.
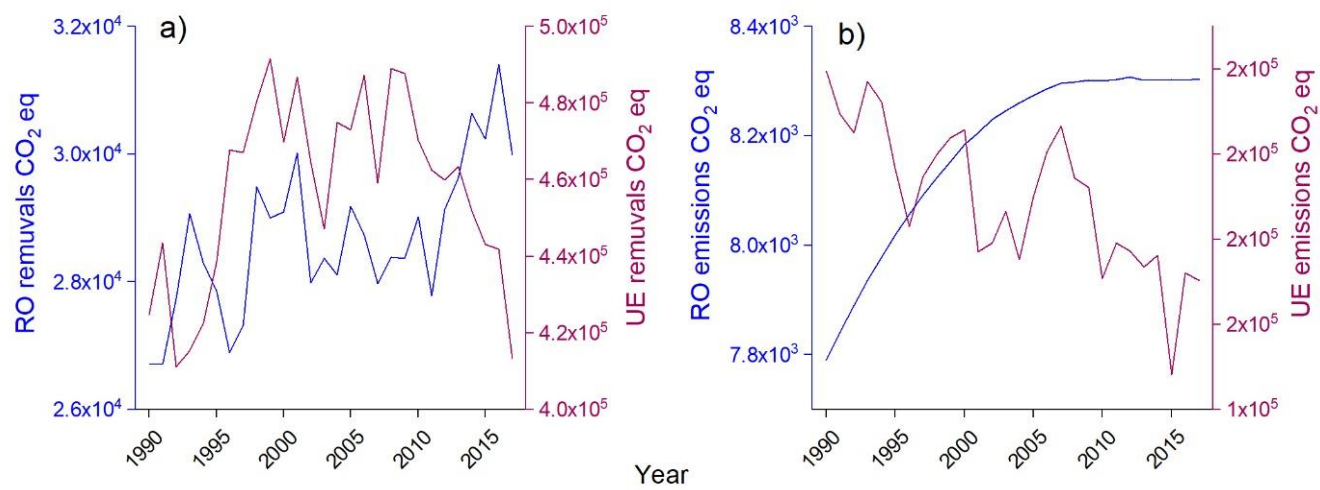

Figure 1. Comparative evolution of $\mathrm{GHG}_{\mathrm{s}}$ removal (a) and emission (b) from the LULUCF sector in EU-28 and Romania between 1990-2017 (thousands of tons $\mathrm{CO}_{2}$-eq.). Source: Graph built by the authors based on the information provided by the National Greenhouse Gas Inventory (INGES), www.UNFCCC.com

It was observed that the gross removal in the EU-28 had a different evolution over the two analyzed periods. Between 1990 and 2005, the total amount of removal was approximately 455 million tons of $\mathrm{CO}_{2}$-eq./year, which increased by 3.2 million tons of $\mathrm{CO}_{2}$-eq./year on average, which was equivalent to an average annual rate of $0.7 \%$ /year. After 2005, the yearly average amount of removal increased to approximately 462 million tons of $\mathrm{CO}_{2}$-eq. The results indicated a decrease of approximately 5 million tons of $\mathrm{CO}_{2}$ eq. every year on average, respectively, at a rate of $1.1 \% / y e a r$. The negative trend recorded after 2005 determined that over the period from 1990-2017, there was an average annual decrease of 457 million tons of $\mathrm{CO}_{2}$-eq., with an average rate of $0.1 \%$ /year.

In Romania, the total absorption of the LULUCF sector increased. Between 1990 and 2005, the average annual amount absorbed in $\mathrm{CO}_{2}$-eq. was 28.2 million tons. The average amount absorbed increased by 165 thousand tons of $\mathrm{CO}_{2}$-eq./year, which was a rate of $0.6 \% / y e a r$. Between 2005 and 2017, the average total intake was 29.2 million tons of $\mathrm{CO}_{2}$-eq., a value that increased yearly by 67 thousand tons of $\mathrm{CO}_{2}$-eq., with a rate of $0.2 \%$ year. The values reported from 2005-2017 were lower than those in the previous period (1990-2005), which determined the average annual amount absorbed by 28.7 million tons of $\mathrm{CO}_{2}$-eq./year. This means an average annual rate of $0.4 \%$ for an average yearly increase of 121 thousand tons of $\mathrm{CO}_{2}$-eq. absorbed per year. The total absorbed quantity that was registered in Romania from the LULUCF sector represented an increasing share of the total gross absorption in the EU-28, from $6.3 \%$ in 1990 to $7.3 \%$ in 2017 . This finding can be explained by the more rapid increase in intake in Romania ( $0.4 \%$ /year) compared to the tendency of decreasing gross absorption at the EU-28 level (-0.1\%/year).

The emissions of $\mathrm{CO}_{2}$-eq. from the LULUCF sector, are much lower than the gross $\mathrm{CO}_{2}$-eq. removal (Fig. 1b). At EU-28, the total withdrawals are approximately 2.8 times 
higher than emissions, and in Romania, this ratio is 3.5. The fact that the gross removal values are several times higher than the emissions makes the LULUCF sector a net absorber (Table 2). We noted that in the EU-28, the annual average quantity of $\mathrm{GHG}_{\mathrm{CO}_{2} \text {-eq. }}$. emissions was higher in the 1990-2005 period than that recorded in the 2005-2017 period. In Romania, the yearly average amount of $\mathrm{GHG}_{\mathrm{CO}_{2} \text {-eq. }}$ emissions increased in the 19902005 period compared to that in the 2005-2017 period. The $\mathrm{GHG}_{\mathrm{CO}_{2} \text {-eq. }}$ generated by the LULUCF sector decreased to an average annual rate of $0.5 \%$ per year in the EU-28. In Romania, this emission increased by approximately $0.2 \%$ on average per year (Table 2 ).

Table 2. Synthetic comparative indicators of the evolution of $\mathrm{GHG}_{\mathrm{CO}_{2} \text {-eq. }}$ from the LULUCF sector (period 1990-2017)

\begin{tabular}{|c|c|c|c|c|c|c|}
\hline \multirow{2}{*}{ Time } & \multicolumn{2}{|c|}{$\begin{array}{c}\text { The average annual } \\
\text { level, thousand tons } \\
\text { CO }_{2} \text {-eq/year }\end{array}$} & $\begin{array}{c}\text { The absolute average } \\
\text { change, thousand tons } \\
\text { COO-eq/year }\end{array}$ & \multicolumn{2}{|c|}{$\begin{array}{c}\text { Rate average annual } \\
\text { \% }\end{array}$} \\
\cline { 2 - 7 } & EU-28 & RO & EU-28 & RO & EU-28 & RO \\
\hline $\mathbf{1 9 9 0 - 2 0 0 5}$ & 168,599 & 8,080 & -986 & 32 & $-0.6 \%$ & $0.4 \%$ \\
\hline $\mathbf{2 0 0 5 - 2 0 1 7}$ & 160,412 & 8,299 & -820 & 2 & $-0.5 \%$ & $0.0 \%$ \\
\hline $\mathbf{1 9 9 0 - 2 0 1 7}$ & 164,927 & 8,175 & -912 & 19 & $-0.5 \%$ & $0.2 \%$ \\
\hline
\end{tabular}

The average growth rate of gross removal in Romania was $0.4 \% / y e a r$, which was higher than the $\mathrm{CO}_{2}$-eq. emissions (+ $0.2 \%$ /year), and the high value of $\mathrm{CO}_{2}$-eq. intake indicates that the LULUCF sector is a net absorber (Fig. 2a). In the 1990s, the total removal decreased in the EU-28 compared to the values recorded in Romania. The full removal of $\mathrm{CO}_{2}$-eq. increased steadily in Romania compared to in the EU-28, especially after 2011 (Fig. 2b). One aspect of the analysis is the absorption capacity of $\mathrm{CO}_{2}$-eq. from the LULUCF sector at the level of the whole economic unit. The measure was an indicator called the degree of $\mathrm{CO}_{2}$-eq. absorption, which is determined as a percentage ratio between the active $\mathrm{CO}_{2}$-eq. intake in the LULUCF sector and the total amount of $\mathrm{CO}_{2}$-eq. emitted from sources other than LULUCF throughout the economy. Active absorption means the effective incorporation of $\mathrm{CO}_{2}$-eq. by the forest and pasture areas without considering the carbon dioxide incorporated in wood products (HWP).

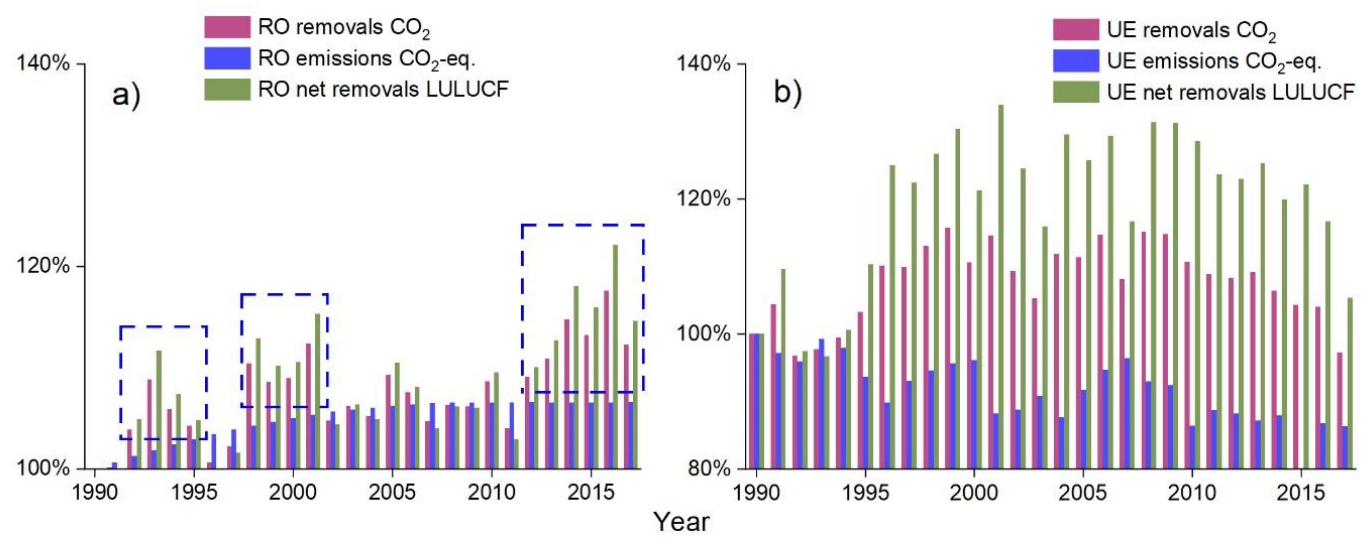

Figure 2. Comparative dynamics of the emission/removal of $\mathrm{GHG}_{\mathrm{CO}_{2} \text {-eq. }}$ from the LULUCF sector in (a) Romania and (b) EU-28 between 1990-2017 (1990 = 100\%). Source: Graph built by the authors based on information provided by the National Greenhouse Gas Inventory (INGES) 2019, 


\subsection{Analysis of the dynamics of emissions/removals in the LULUCF sector in Romania}

In the period from 1990-2017, approximately 28.54 million $\mathrm{CO}_{2}$-eq./year was absorbed, and the emissions were at an average level of 8.16 million tons of $\mathrm{CO}_{2}$-eq./year. Thus, an average annual level of net absorption of 20.39 million tons of $\mathrm{CO}_{2}$-eq./year was observed during the analyzed period. In 2017, compared to 1990, the total intake increased by $21.3 \%$, which represented an increase of approximately 5.3 million $\mathrm{CO}_{2}$-eq. In 2017, compared to 2005 , there was an increase of $2.8 \%$. The increase was slightly over 800 thousand tons of $\mathrm{CO}_{2}$-eq.

The $\mathrm{GHG}_{\mathrm{CO}_{2} \text {-eq. }}$ emissions in the LULUCF sector in 2017, in comparison with those in 1990 , increased by $8.7 \%$ and 667 thousand tons of $\mathrm{CO}_{2}$-eq., respectively. In comparison with 2005 , the emissions increased by $0.4 \%$, which was equivalent to 29,181 thousand tons of $\mathrm{CO}_{2}$-eq. (Table 3).

Table 3. Dynamics of $\mathrm{GHG}_{\mathrm{CO}_{2-\mathrm{e}}}$ emissions and removals from the LULUCF sector in Romania between 1990 and 2017

\begin{tabular}{|c|c|c|c|}
\hline Year & $\begin{array}{c}\text { Removals CO} \mathbf{2}_{\mathbf{-}} \mathbf{e q} \\
(-)\end{array}$ & $\begin{array}{c}\text { Emissions CO} \mathbf{2}^{-} \\
\text {eq/year }(+)\end{array}$ & $\begin{array}{c}\text { LULUCF RO } \\
(-)\end{array}$ \\
\hline & & $\begin{array}{c}\text { thousands of tons of } \\
\mathrm{CO}_{2} \text { equivalent }\end{array}$ & \\
\hline $\mathbf{A}$ & $(1)$ & $(2)$ & $(3)=(1)-(2)$ \\
\hline $\mathbf{1 9 9 0}$ & 24,710 & 7,637 & 17,073 \\
\hline $\mathbf{2 0 0 5}$ & 29,181 & 8,274 & 20,906 \\
\hline $\mathbf{2 0 1 7}$ & 29,984 & 8,304 & 21,680 \\
\hline
\end{tabular}

The tendency of the increase of the gross absorption to be higher than the trend of the evolution of the emissions determined an intake of net absorption in 2017 compared to in 1990 , representing an increase of $27 \%$. The increase was 4.6 million $\mathrm{CO}_{2}$-eq., and in comparison, with 2005, the net quantity of absorbed $\mathrm{CO}_{2}$-eq. increased by 774 thousand tons, representing an increase of 3.7\%. We noted that in the 1990-2005 period, the gross absorption increased by $1.05 \%$ per year, with 279 thousand tons of $\mathrm{CO}_{2}$-eq./year compared to the emissions that grew by only $0.5 \%$ per year. An increase in the absolute figures of 40 thousand tons of $\mathrm{CO}_{2}$-eq was observed. Throughout the analyzed period, net absorption increased by 240 thousand tons of $\mathrm{CO}_{2}$-eq., with an annual average rate of $1.27 \%$ per year (Fig. 3c). In the 2005-2017 period, the growth rates of gross absorption and net emissions/removals in the LULUCF sector were as follows: gross absorption slowed down to $0.23 \%$ per year, emissions to $0.03 \%$ /year, and net absorption to $0.3 \%$ /year (Fig. 3a).

Another aspect of the LULUCF analysis for Romania was the difference in reporting of the dynamics, either in the reference to 1990 or 2005, when the European Union started to apply a series of policies and measures to reduce greenhouse gases to reach the targets. The dynamics of emissions increased compared to those in 1990, stabilizing this increase up to $10 \%$, and compared to that in 2005 , the emissions curve remained relatively constant (Fig. 3a, b). The absorption had an evident tendency of accentuated growth compared to that in 1990, and, this increase was especially present after 2011 in comparison to 2005. 

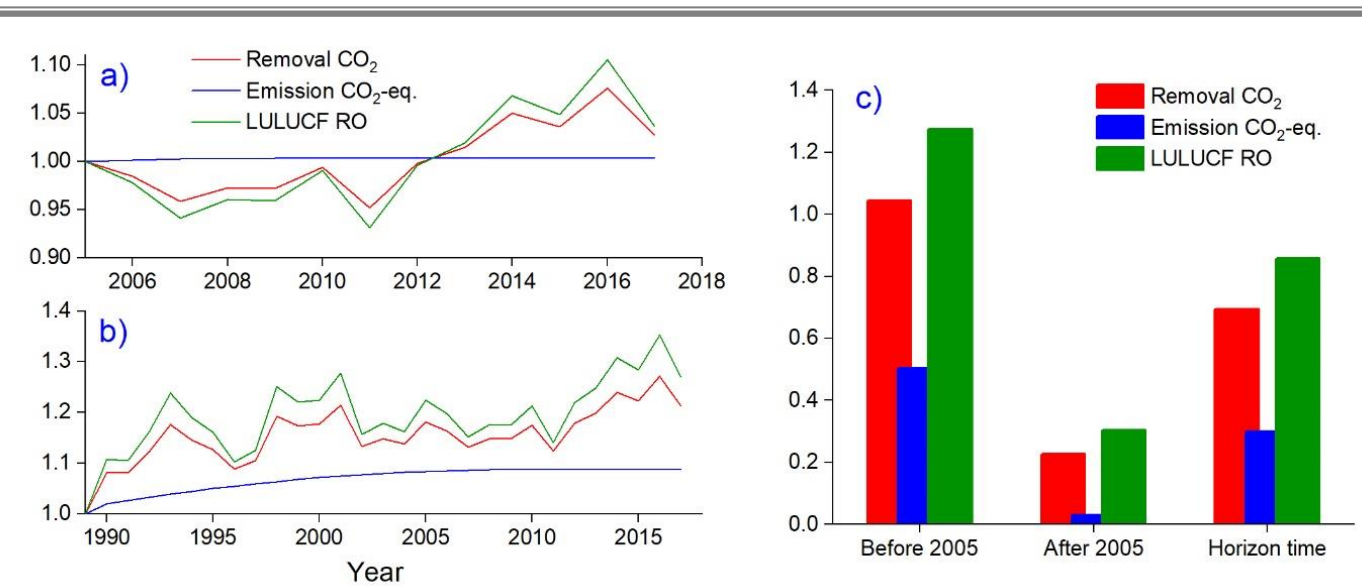

Figure 3. Comparative dynamics of gross absorption, net emission and removal of LULUCF sector in Romania a) considering 2005 the reference (100\%); b) the reference was established $1990(100 \%)$; c) the dynamics of total removal, emissions and net absorption of the LULUCF sector in Romania.

\subsection{Evolution of the dynamics of the chemical composition of GHG emissions in the LULUCF sector in Romania}

The main components of GHG emissions in the LULUCF sector are carbon dioxide, methane and nitrous oxide. The only chemical element absorbed is carbon dioxide. The net absorbent characteristics of the LULUCF sector is given by the considerable amount of gross absorption of carbon dioxide compared to the quantities emitted of other gaseous components. Another feature is related to the property of the LULUCF sector of absorbing carbon dioxide from different economic areas. In terms of the quantities of compounds emitted or absorbed, carbon dioxide is by for most important, the next is nitrous oxide, and the last is methane.

In 2017, the amount of $\mathrm{GHG}_{\mathrm{CO}_{2} \text {-eq. }}$ emitted from LULUCF was 8.3 million tons $\mathrm{CO}_{2}$ eq., which was $8.7 \%$ higher than that in 1990 (7.64 million tons $\mathrm{CO}_{2}$-eq.) and was $0.4 \%$ than that in 2005 (over 8.27 million tons $\mathrm{CO}_{2}$-eq.). Table 4 indicates an increase in the quantity of $\mathrm{GHG}_{\mathrm{CO}_{2} \text {-eq. }}$ of more than 666 thousand tons of $\mathrm{CO}_{2}$-eq. in 2017 when compared to that in 1990. Over $90 \%$ of the growth resulted from nitrous oxide emissions and methane emissions, which together accounted for almost $0.3 \%$ of the growth, and carbon dioxide emissions represented 9.3\%. In observing 2017 versus 2005, it can be seen that the $\mathrm{GHG}_{\mathrm{CO}_{2} \text {-eq. }}$ increased by only 29.32 thousand tons $\mathrm{CO}_{2}$-eq., indicating a lower amount of approximately $96 \%$ than in the previous comparison. Furthermore, nitrous oxide contributed to the increase in 2017 compared to 2005 by approximately $94 \%$, and the methane contributed only $6 \%$. The rate of carbon dioxide was relatively constant after 2005 , which made the contributions to the previous growth irrelevant.

Table 4. Absolute change of emissions of GHG LULUCF chemicals (thousand tons $\mathrm{CO}_{2}$-eq)

\begin{tabular}{|c|c|c|}
\hline $\mathbf{2 0 1 7}$ & $\begin{array}{c}\text { Compared to } \\
\mathbf{1 9 9 0}\end{array}$ & $\begin{array}{c}\text { Compared to } \\
\mathbf{2 0 0 5}\end{array}$ \\
\hline Emission $\mathbf{C O}_{\mathbf{2}}(+)$ & 62.23 & 0.00 \\
\hline Emission $\mathbf{C H}_{\mathbf{4}}(+)$ & 1.90 & 1.82 \\
\hline Emission $\mathbf{N}_{\mathbf{2}} \mathbf{O}(+)$ & 602.46 & 27.49 \\
\hline Total emission, eq $\mathbf{C O}_{\mathbf{2}}(+)$ & 666.60 & 29.32 \\
\hline
\end{tabular}


We noted that methane had a significant growth trend. In contrast, carbon dioxide had a relatively constant evolution, and the increase in nitrous oxide moderately accelerated until 2005, after which the value remained relatively constant until 2017 (Fig. 4a).
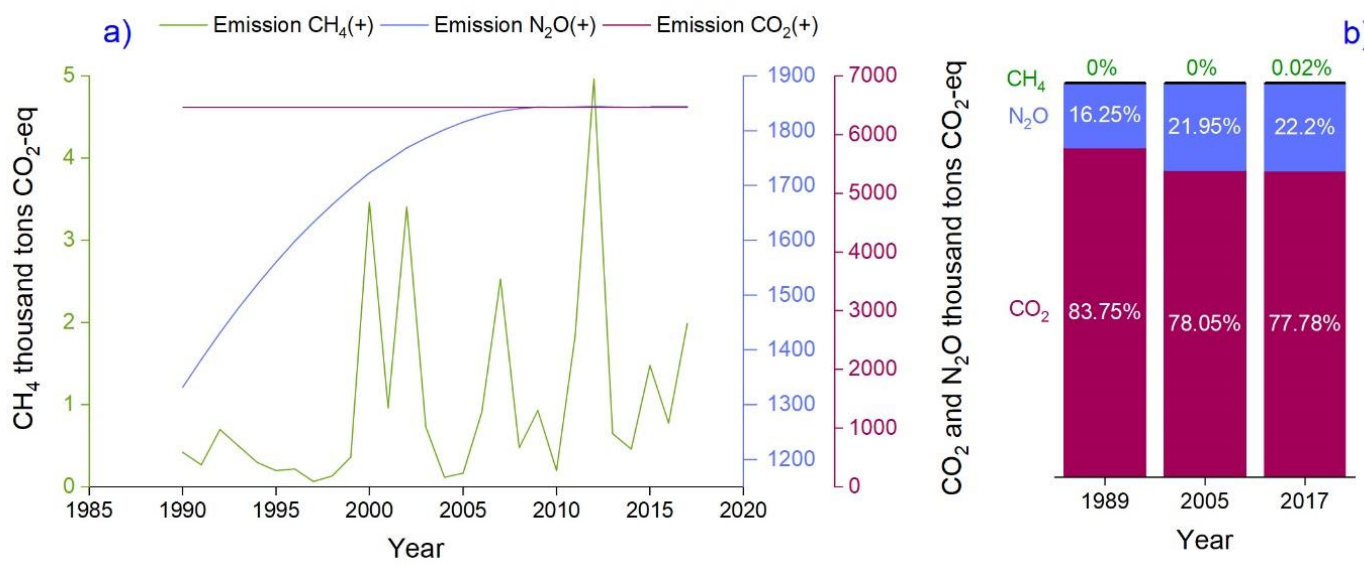

Figure 4. a) the dynamics of the chemical components of the $\mathrm{GHG}_{\mathrm{CO}_{2} \text {-eq. }}$ emissions from the LULUCF sector (period 1990-2017); b) the weight of $\mathrm{GHG}_{\mathrm{CO}_{2} \text {-eq. }}$ emissions after the chemical structure LULUCF in Romania

At the level of the LULUCF sector, in the total $\mathrm{GHG}_{\mathrm{CO}_{2} \text {-eq. }}$ emissions, we noted that in 1990 , the amount of carbon dioxide was approximately $84 \%$, which decreased slowly to $78 \%$ in 2017 (Fig. 4b). Nitrous oxide made up 16.25\% of the emissions in 1990, and in 2005 , it exceeded one-fifth of the total $\mathrm{GHG}_{\mathrm{CO}_{2} \text {-e }}$ emissions from the LULUCF sector. Methane made up only a small part of the emissions and had an increasing trend (Fig. 4a). Before 2005, the quantity of $\mathrm{GHG}_{\mathrm{CO}_{2} \text {-eq. }}$ at the LULUCF level increased at an average rate of $0.5 \% / y e a r$, with 40 thousand tons of $\mathrm{CO}_{2}$-eq./year. After 2005, the registered values slightly increased by $0.03 \% / y e a r ;$ the increase was approximately 2 thousand tons of $\mathrm{CO}_{2}$ eq./year (Table 5).

Table 5. Average annual $\mathrm{GHG}_{\mathrm{CO}_{2} \text {-eq. }}$ emissions from LULUCF following chemical structure (thousand tons $\mathrm{CO}_{2}$-eq)

\begin{tabular}{|c|c|c|c|c|}
\hline Year & $\begin{array}{c}\text { Total emissions, } \\
\mathbf{C O}_{\mathbf{2}} \text {-eq (+) }\end{array}$ & $\begin{array}{c}\text { Emission } \\
\mathbf{C O}_{\mathbf{2}}(+)\end{array}$ & $\begin{array}{c}\text { Emission } \\
\mathbf{C H}_{\mathbf{4}}(+)\end{array}$ & $\begin{array}{c}\text { Emission } \\
\mathbf{N}_{\mathbf{2}} \mathbf{O}(+)\end{array}$ \\
\hline $\mathbf{1 9 9 0 - 2 0 0 5}$ & 8,054 & 6,455 & 0.71 & 1,599 \\
\hline $\mathbf{2 0 0 5 - 2 0 1 7}$ & 8,299 & 6,458 & 1.34 & 1,839 \\
\hline $\mathbf{1 9 9 0 - 2 0 1 7}$ & 8,156 & 6,456 & 1.01 & 1,699 \\
\hline
\end{tabular}

From 1990-2017, the $\mathrm{GHG}_{\mathrm{CO}_{2} \text {-eq. }}$ emissions in the LULUCF sector had a slight growth trend, with an average rate of $0.3 \%$ per year, which in absolute numbers represented an average increase of 24 thousand tons of $\mathrm{CO}_{2}$-eq. The amount of carbon dioxide emissions recorded an average annual rate of $0.1 \%$ per year between 1990 and 2005 , with an average yearly increase of 3.9 thousand tons of $\mathrm{CO}_{2}$-eq./year. In the 20052017 period, the emissions of carbon dioxide remained constant. Throughout the analyzed time span from $1990-2017$, the average annual rate was $0.035 \%$ per year, amounting to 2.2 thousand tons of $\mathrm{CO}_{2}$ (Table 6). 
Mihaela Iordache, Ramona Zgavarogea, Andreea Maria Iordache, Marius Constantinescu, Felicia Bucura, Roxana Elena Ionete, Remus Grigorescu, Constantin Nechita

Table 6. Mean change absolute $\mathrm{GHG}_{\mathrm{CO}_{2} \text {-eq. }}$ emissions in the LULUCF sector in Romania during 1990-2017, (thousand tons $\mathrm{CO}_{2}$-eq)

\begin{tabular}{|c|c|c|c|c|}
\hline Year & $\begin{array}{c}\text { Total } \\
\text { emissions, } \\
\text { eq } \mathbf{C O}_{\mathbf{2}}(+)\end{array}$ & $\begin{array}{c}\text { Emission } \mathbf{C O}_{\mathbf{2}} \\
(+)\end{array}$ & $\begin{array}{c}\text { Emission } \mathbf{C H}_{\mathbf{4}} \\
(+)\end{array}$ & $\begin{array}{c}\text { Emission } \mathbf{N}_{\mathbf{2}} \mathbf{O} \\
(+)\end{array}$ \\
\hline $\mathbf{1 9 9 0 - 2 0 0 5}$ & 40.0 & 3.9 & 0.0050 & 35.9 \\
\hline $\mathbf{2 0 0 5 - 2 0 1 7}$ & 2.0 & 0.0 & 0.15 & 2.0 \\
\hline $\mathbf{1 9 9 0 - 2 0 1 7}$ & 24 & 2.2 & 0.068 & 22 \\
\hline
\end{tabular}

The methane emissions recorded a growth trend with an average rate of $4.2 \%$ per year, amounting to an increase of 5 tons of $\mathrm{CO}_{2}$-eq./year in the interval 1990-2005. After 2005 , methane registered an accentuated growth of approximately $23 \%$ from one year to another, and methane emissions increased by 150 tons of $\mathrm{CO}_{2}$-eq. (more than 30 times higher than that during the 1990-2005 period). The accelerated growth trend of methane emissions from 2005-2017 influenced the $\mathrm{GHG}_{\mathrm{CO}_{2} \text {-eq. }}$. Moreover, methane emissions have increased during the last 30 years at an average annual rate of $11.8 \%$ per year, which in absolute figures represented an increase of approximately 70 thousand tons of $\mathrm{CO}_{2}$-eq. (Table 6).

Nitrous oxide recorded a rapid growth trend between 1990 and 2005, with an increase of 36 thousand tons of $\mathrm{CO}_{2}$-eq./year, for an annual average rate of $2.4 \%$. After 2005 , the growth trend was insignificant at only $0.1 \%$ per year, representing only 2 thousand tons of $\mathrm{CO}_{2}$-eq. During the time span analyzed, the growth tendency of nitrous oxide reached an annual average rate of $1.4 \%$ per year, indicating an increase from one year to another of 22 thousand tons of $\mathrm{CO}_{2}$-eq. (Table 6).

Between 1990 and 2017, total carbon dioxide absorption increased by $0.9 \%$ per year, representing 186 thousand tons of $\mathrm{CO}_{2}$-eq./year. The methane absorption also increased by $11.7 \%$ per year, representing an average annual increase of 68 tons of $\mathrm{CO}_{2}$-eq./year. $\mathrm{We}$ noted a significant increasing trend of methane, compared to the other two components, which was not worrying considering that $\mathrm{GHG}_{\mathrm{CO}_{2-\mathrm{e}}}$ emissions from LULUCF's were almost nonexistent (with the highest amount being in 2012 of $0.27 \%$ ). Otherwise, the shares were well below $0.2 \%$ of the emissions from the LULUCF sector.

\subsection{Analysis of the evolution of $\mathrm{GHG}_{\mathrm{CO}_{2} \text {-eq. }}$ emissions in the LULUCF sector in Romania by land}

In Table 7, we show the dynamics of $\mathrm{GHG}_{\mathrm{CO}_{2} \text {-eq. }}$ emissions in Romania in the LULUCF sector between 1990 and 2017. The trends in the evolution of emissions by geographical areas specific to the LULUCF sector were significant before 2005. After 2005, they stabilized around values that remained unchanged. Most of the components in

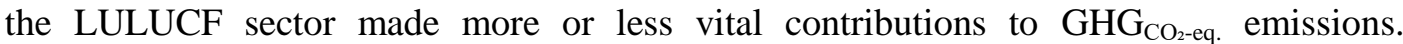
"Settlements" had a share of approximately $50 \%$ in 1990, and this share decreased in both 2005 and 2017 to approximately $47.5 \%$. The "wetlands" emitted approximately one-fifth of the $\mathrm{GHG}_{\mathrm{CO}_{2} \text {-eq. }}$ at the LULUCF level in 1990 and represented a stock that subsequently stabilized at approximately $18.7 \%$. The "other lands" area of the LULUCF sector increased from $17 \%$ in 1990 to over $22 \%$ in 2005 and 2017. The other two industries remained relatively constant over time ("cultivated lands" and "pastures") (Fig. 5a). 
Table 7. Dynamics of $\mathrm{GHG}_{\mathrm{CO}_{2} \text {-eq. }}$ emissions in Romania in the LULUCF sector between 1990-2017 (thousand tons of $\mathrm{CO}_{2}-\mathrm{eq}$ ).

\begin{tabular}{|c|c|c|c|c|c|c|c|}
\hline Year & $\begin{array}{c}\text { A. } \\
\text { Forest } \\
\text { land }\end{array}$ & $\begin{array}{c}\text { B. } \\
\text { Cropland }\end{array}$ & $\begin{array}{c}\text { C. } \\
\text { Grassland }\end{array}$ & $\begin{array}{c}\text { D. } \\
\text { Wetlands }\end{array}$ & $\begin{array}{c}\text { E. } \\
\text { Settlements }\end{array}$ & $\begin{array}{c}\text { F. } \\
\text { Other } \\
\text { lands }\end{array}$ & $\begin{array}{c}\text { Total } \\
\text { emissions }\end{array}$ \\
\hline $\mathbf{1 9 9 0}$ & 27 & 405 & 562 & 1,531 & 3,811 & 1,301 & 7,637 \\
\hline $\mathbf{2 0 0 5}$ & 27 & 426 & 485 & 1,549 & 3,932 & 1,856 & 8,274 \\
\hline $\mathbf{2 0 1 7}$ & 29 & 426 & 485 & 1,549 & 3,932 & 1,883 & 8,304 \\
\hline
\end{tabular}

The "other lands" area registered increased $\mathrm{GHG}_{\mathrm{CO}_{2} \text {-eq. }}$ emissions in 2017 compared to the reference year (45\%) in 2005 (1.4\%). Additionally, before 2005, the average annual growth rate of emissions was $2.2 \%$ per year, with an average yearly growth of 34.6 thousand tons of $\mathrm{CO}_{2}$-eq./year. After 2005, the growth rate decreased compared to the previous period by approximately $0.1 \%$ per year, with an average annual growth of 2.2 thousand tons of $\mathrm{CO}_{2}$-eq. Between 1990 and 2017, the $\mathrm{GHG}_{\mathrm{CO}_{2} \text {-eq. }}$ emissions increased by $1.3 \%$ per year, increasing by 20.76 thousand tons $\mathrm{CO}_{2}$-eq. This amount was the most substantial absolute annual average increase compared to the other components of the LULUCF sector.

In the period of 1990-2005, the $\mathrm{GHG}_{\mathrm{CO}_{2} \text {-eq. }}$ emissions from the forest areas remained constant, whereas after 2005, the emissions increased by approximately $0.5 \%$ per year, which represented 200 tons of $\mathrm{CO}_{2}$-eq./year. Before 2005, the emissions from "cultivated land" grew by $0.3 \%$ annually on average, amounting to 1.3 thousand tons of $\mathrm{CO}_{2}$-eq. After 2005, they remained constant at 426 thousand tons of $\mathrm{CO}_{2}$-eq. (Fig. 5a).
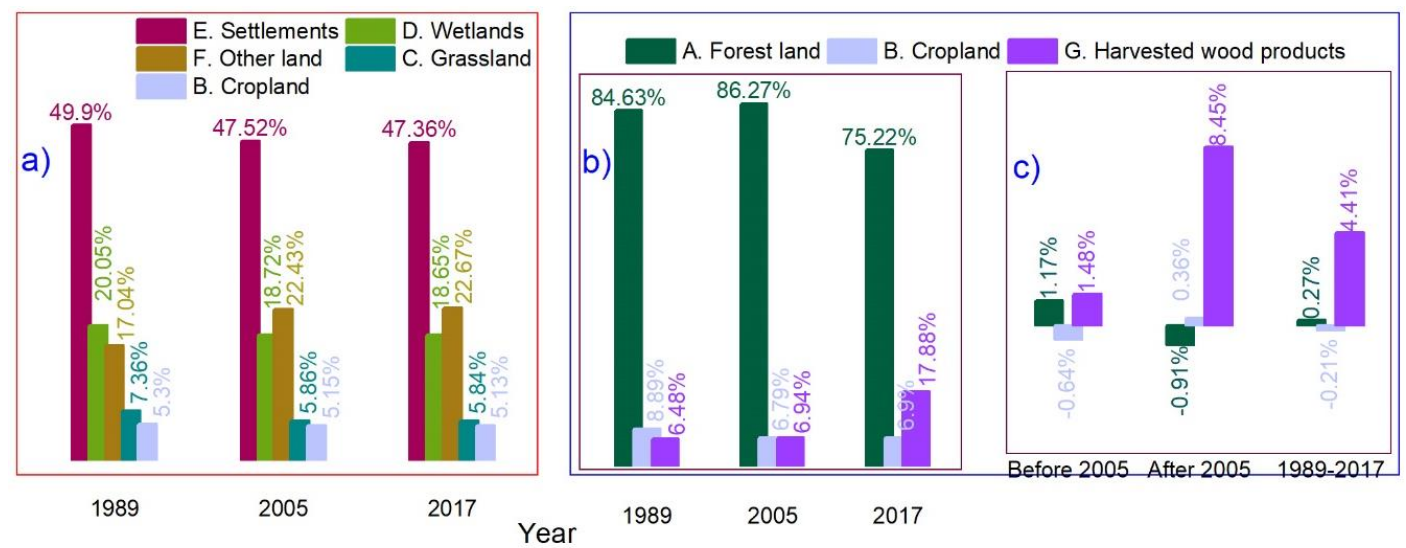

Figure 5. a) the dynamics of LULUCF components regarding $\mathrm{GHG}_{\mathrm{CO}_{2} \text {-eq. }}$ emission; b) the dynamics of the structure of $\mathrm{GHG}_{\mathrm{CO}_{2} \text {-eq }}$ removal in the LULUCF sector in Romania by the geographical structure; c) the dynamics of LULUCF components in terms of $\mathrm{GHG}_{\mathrm{CO}_{2} \text {-eq. }}$ removal.

An emission reduction of approximately 4.8 thousand tons of $\mathrm{CO}_{2}$-eq., representing a decrease at an average annual rate of $0.9 \% / y e a r$, was observed for the grassland areas. After 2005, the share of this land-use type remained constant at approximately 485 thousand tons annually. The absorption dynamics of the "wood products" area were different from the evolution of the absorption capacity in the forestland and cultivated land in the LULUCF sector. In both subperiods, the absorption showed average annual growth rates, as shown in Fig. 5b. 
The high share of forestland in the absorption of GHG amounted to over $84 \%$ in 1990 in contrast to the cultivated areas and the products obtained from wood. In 2005, this share increased slightly to approximately $86.3 \%$, reaching just over $75 \%$ in 2017 - the absorption of forestland accumulates in stocks of wood products. The percentage of wood products increased from $6.9 \%$ in 2005 to approximately $18 \%$ in 2017.

The share of wood products increased after 2005 , from $6.9 \%$ to approximately $18 \%$ in 2017. In 2017, the absorption capacity of the forestland increased compared to the reference year by $7.8 \%$, and compared to 2005 , it decreased by $10.4 \%$. The rate of decrease recorded compared to 2005 was higher in absolute value compared to the growth rate recorded in 2017. Cultivated land had 5.8\% lower absorption in 2017 compared to in 1990, and a positive trend of $4.4 \%$ was calculated in 2017 compared to in 2005 . The intake of the wood product area registered a substantial increase by 3.3 times in 2017 compared to the reference year; the growth was 2.6 times in 2017 compared to in 2005. Before 2005, the absorption in forestland increased at an average annual rate of approximately $1.2 \%$. This rate did not continue into the immediately subsequent period, when intake decreased at an average yearly rate of approximately $0.9 \%$ per year. This situation led to a slight increase of $0.3 \%$ in the absorption per year over the analyzed time horizon. We also noted that before 2005, the absorption capacity increased by 266 thousand tons of $\mathrm{CO}_{2}$-eq./year, and after 2005, it decreased by 218 thousand tons of $\mathrm{CO}_{2}$-eq. The evolution after 2005 practically determined the offset of the growth from the previous period (Fig. 5b).

The absorption in the area of cultivated land decreased by $0.6 \% / y e a r$ from 1990 2005 by 13 thousand tons of $\mathrm{CO}_{2}$-eq./year. After 2005, an average annual increase in absorption of $0.4 \%$ year and an absolute average increase of 7 thousand tons of $\mathrm{CO}_{2}-$ eq./year can be observed. In the analyzed time span, the average year-over-year rate decreased by $0.2 \%$ per year, which is expressed in absolute figures of 5 thousand tons of $\mathrm{CO}_{2}$-eq./year (Table 7). Thus, before 2005, an absorption rate of approximately $1.5 \%$ per year was calculated in absolute figures of 27 thousand tons of $\mathrm{CO}_{2}$-eq. This was approximately 5.7 times higher than the 2005 share, reflecting an increase in quantity by over 10 times on average/year. This situation explains the rapid growth in the percentage of this component in the total LULUCF absorption as opposed to that of forestland (see Fig. 5c).

\section{CONCLUSIONS}

The study proposed recording of greenhouse gases from land use, land-use change and forestry activities (LULUCF) for the EU-28 member states from 1990-2017. The emissions/removals evolution from the Romania and EU-28 LULUCF sectors, were compared. The results indicated that in the EU-28, net removals in the LULUCF sector increased before 2005 with, at the average yearly value of 301.3 million tons of $\mathrm{CO}_{2}$-eq./year, an average annual net amount was absorbed, representing 292.5 million tons of $\mathrm{CO}_{2}$-eq./year. For Romania, the average yearly level of absorption in the LULUCF sector was approximately 20.2 million tons of $\mathrm{CO}_{2}$-eq/year during the 1990-2005 period. After 2005, the average annual level increased to approximately 21.0 million tons of $\mathrm{CO}_{2}$-eq/year. In both periods analyzed in Romania, the net absorption, which was compared to that in the EU-28, was multiplied by 133 thousand tons of $\mathrm{CO}_{2}$-eq. in the 1990-2005 period. Furthermore, in the 2005-2017 period, only 64 thousand tons $\mathrm{CO}_{2}$-eq./year were reported.

In Romania during the period from 1990-2017, approximately 28.54 million $\mathrm{CO}_{2^{-}}$ eq./year was absorbed, and the net emissions were at an average level of 8.16 million tons of $\mathrm{CO}_{2}$-eq./year. The $\mathrm{GHGCO}_{2}$-eq. emissions in the LULUCF sector increased by $8.7 \%$ in 2017 compared to $0.4 \%$ in 2005 when 1990 was used as a reference. The main components of GHG emissions indicated different trends. Thus, the carbon dioxide had a relatively 
constant evolution, methane had a significant growth tendency, and nitrous oxide increased moderately until 2005, after which the value remained relatively constant until 2017 . The methane emissions recorded a growth trend at an average rate of $4.2 \%$ per year in the interval from 1990-2005 and 23\% between 2005 and 2019. Nitrous oxide exhibited a rapid growth trend between 1990 and 2005, with an annual average rate of $2.4 \%$ per year, and after 2005 , only $0.1 \%$ per year.

The Paris Agreement indicated a systematic approach of greenhouse gas emission statistics for each sector to easily assess different trends over time. Considering this purpose, specific policies and action plans for each sector need to be developed and, in many cases, improved based on accurate GHG statistics. The results discussed in this study will help national decision makers comprehend new alternatives for reducing greenhouse gas emissions and increasing absorption.

The results presented in this study are meant to contribute to implementing environmental effective policies, to encourage the development of renewable, recyclable and sustainable energy sources, together with arousing the interest of all parties involved, from common people to decision makers, to preserve the biodiversity and make the breathable air a clean and healthy environment for everyone.

\section{Highlights:}

- In Romania, the total absorption of the LULUCF sector has increased.

- The emissions of $\mathrm{CO}_{2}$-eq. were lower than the removal $\mathrm{CO}_{2}$-eq. by the LULUCF sector.

- $\mathrm{CH}_{4}$ had a significant growth trend in contrast with that of $\mathrm{CO}_{2}$, which was relatively constant.

- The GHG absorption of forestland amounted to over 84\% in 1990 and only 75\% in 2017.

- This paper can be used to develop strategies to meet sustainable development goals (SDGs).

Acknowledgements: The work was supported by the Romanian Ministry of Research and Innovation - grants number: PN19070502 "Transdisciplinary assessment of decline oak trees in the extra-Carpathian area, affected by the current environmental changes - adaptation, mitigation and risk" and PN 19110303 "Advanced techniques for identifying sources of contamination and biochemical reactions in aquatic ecosystems".

Funding: Project PN 19110303, Contract no. 9N/2019, financed by the Ministry of Education and Research, Romania.

Author contributions: M.I., R.Z. wrote the original draft, and all authors contributed to the analysis and article review. Figures were created by R.E.I., R.G. and C.N. coordinated the analysis for this paper. The policy inventory and database were created by M.C and F.B. The scenario database was coordinated by M.I., R.Z. and A.M.I. All authors have formulated the conclusions.

Conflict of Interest Statement: The authors declare no conflicts of interest associated with this manuscript.

\section{REFERENCES}

Benndorf, R., Federici, S., Forner, C., Pena, N., Rametsteiner, E., Sanz, M.J., Somogyi, Z., 2007. Including land use, land-use change, and forestry in future climate change, agreements: thinking outside the box. Environ. Sci. Policy 10, 283-294. https://doi.org/10.1016/j.envsci.2006.10.011

Berglund, Ö., Berglund, K., 2010. Distribution and cultivation intensity of agricultural peat and gyttja soils in Sweden and estimation of greenhouse gas emissions from cultivated peat soils. Geoderma 154, 173-180. https://doi.org/10.1016/j.geoderma.2008.11.035 
Mihaela Iordache, Ramona Zgavarogea, Andreea Maria Iordache, Marius Constantinescu, Felicia Bucura, Roxana Elena Ionete, Remus Grigorescu, Constantin Nechita

Ellison, D., Lundblad, M., Petersson, H., 2014. Reforming the EU approach to LULUCF and the climate policy framework. Environ. Sci. Policy 40, 1-15. https://doi.org/10.1016/j.envsci.2014.03.004

Ellison, D., Lundblad, M., Petersson, H., 2011. Carbon accounting and the climate politics of forestry. Environ. Sci. Policy 14, 1062-1078. https://doi.org/10.1016/j.envsci.2011.07.001

European_Commission, 2016. Agriculture and LULUCF in the 2030. https://doi.org/10.2834/818173

Forsell, N., Korosuo, A., Gusti, M., Rüter, S., Havlik, P., Obersteiner, M., 2019. Impact of modelling choices on setting the reference levels for the EU forest carbon sinks: How do different assumptions affect the country-specific forest reference levels? Carbon Balance Manag. 14, 10. https://doi.org/10.1186/s13021-019-0125-9

Fragkos, P., Tasios, N., Paroussos, L., Capros, P., Tsani, S., 2017. Energy system impacts and policy implications of the European Intended Nationally Determined Contribution and low-carbon pathway to 2050. Energy Policy 100, 216-226. https://doi.org/10.1016/j.enpol.2016.10.023

Höhne, N., Wartmann, S., Herold, A., Freibauer, A., 2007. The rules for land use, land use change and forestry under the Kyoto Protocol-lessons learned for the future climate negotiations. Environ. Sci. Policy 10, 353-369. https://doi.org/10.1016/j.envsci.2007.02.001

Jung, M., 2005. The role of forestry projects in the clean development mechanism. Environ. Sci. Policy 8, 87-104. https://doi.org/10.1016/j.envsci.2005.01.001

Keith, H., Vardon, M., Stein, J.A., Lindenmayer, D., 2019. Contribution of native forests to climate change mitigation - A common approach to carbon accounting that aligns results from environmental-economic accounting with rules for emissions reduction. Environ. Sci. Policy 93, 189199. https://doi.org/10.1016/j.envsci.2018.11.001

Kendall, M. G. (1948). Rank correlation methods.

Kissinger, G., Gupta, A., Mulder, I., Unterstell, N., 2019. Climate financing needs in the land sector under the Paris Agreement: An assessment of developing country perspectives. Land use Policy 83, 256-269. https://doi.org/10.1016/j.landusepol.2019.02.007

Kuramochi, T., Wakiyama, T., Kuriyama, A., 2017. Assessment of national greenhouse gas mitigation targets for 2030 through meta-analysis of bottom-up energy and emission scenarios: A case of Japan. Renew. Sustain. Energy Rev. https://doi.org/10.1016/j.rser.2016.12.093

Li, Z., Wang, D., Sui, P., Long, P., Yan, L., Wang, X., Yan, P., Shen, Y., Dai, H., Yang, X., Cui, J., Chen, Y., 2018. Effects of different agricultural organic wastes on soil GHG emissions: During a 4year field measurement in the North China Plain. Waste Manag. 81, 202-210. https://doi.org/10.1016/j.wasman.2018.10.008

Liu, S., Li, Y., Gao, Q., Wan, Y., Ma, X., Qin, X., 2011. Analysis of LULUCF accounting rules after 2012. Adv. Clim. Chang. Res. 2, 178-186. https://doi.org/10.3724/SP.J.1248.2011.00178

Liu, S., Wilkes, A., Li, Y., Gao, Q., Wan, Y., Ma, X., Qin, X., 2016. Contribution of different sectors to developed countries' fulfillment of GHG emission reduction targets under the first commitment period of the Kyoto Protocol. Environ. Sci. Policy 61, 143-153. https://doi.org/10.1016/ j.envsci.2016.04.009

Meehan, F., Tacconi, L., Budiningsih, K., 2019. Are national commitments to reducing emissions from forests effective? Lessons from Indonesia. Forest Policy and Economics, 108, 101968. https://doi.org/10.1016/j.forpol.2019.101968

Miricioiu, M.G., Niculescu, V., Zgavarogea, R., Bublinca, C., Nechifor, G., 2016a. Investigation of carbon dixoide removal from different gases using mixed matrix membranes. 16th International Multidisciplinary Scientific Geoconference, Energy and clean technologies conference proceedings, sgem 2016, vol II, 443-450. DOI: 10.5593/sgem2016B42.

Miricioiu, M.G., Niculescu, V., Constantinescu, M., Zgavarogea, R., Nafliu, M., Nechifor, G., $2016 b$. Development and validation of a chromatographic method for the determination of C1-C8 hydrocarbons, O2, N2 and CO2 in natural gas. Revista de Chimie 67 (11), 2141-2147.

Moe, E., S. Røttereng, J.K., 2018. The post-carbon society: Rethinking the international governance of negative emissions. Energy Res. Soc. Sci. 44, 199-208. https://doi.org/10.1016/j.erss.2018.04.031.

Munawar, S., Khokhar, M.F., Atif, S., 2015. Reducing emissions from deforestation and forest degradation implementation in northern Pakistan. Int. Biodeterior. Biodegrad. 102, 316-323. https://doi.org/10.1016/j.ibiod.2015.02.027.

Pichancourt, J.B., Manso, R., Ningre, F., Fortin, M., 2018. A carbon accounting tool for complex and uncertain greenhouse gas emission life cycles. Environ. Model. Softw. 107, 158-174. 
https://doi.org/10.1016/j.envsoft.2018.06.005.

Pradhan, B.B., Shrestha, R.M., Hoa, N.T., Matsuoka, Y., 2017. Carbon prices and greenhouse gases abatement from agriculture, forestry and land use in Nepal. Glob. Environ. Chang. 43, 26-36. https://doi.org/10.1016/j.gloenvcha.2017.01.005.

Regulation (EU) 2018/841 of the European Parliament and of the Council of 30 May 2018 on the inclusion of greenhouse gas emissions and removals from land use, land use change and forestry in the 2030climate and energy framework, and amending Regulation (EU) No525/2013 and Decision No 529/2013/EU.

Regulation (EU) 2018/842 of the European Parliament and of the Council of 30 May 2018 on binding annual greenhouse gas emission reductions by Member States from 2021 to 2030 contributing to climate action to meet commitments under the Paris Agreement and amending Regulation (EU) No $525 / 2013$.

Schlamadinger, B., Johns, T., Ciccarese, L., Braun, M., Sato, A., Senyaz, A., Stephens, P., Takahashi, M., Zhang, X., 2007. Options for including land use in a climate agreement post-2012: improving the Kyoto Protocol approach. Environ. Sci. Policy 10, 295-305. https://doi.org/10.1016/j.envsci. 2006.12.004.

UNFCCC (1992). "United Nations Framework Convention on Climate Change Article 4, Para 1(a)." IPCC (1995a). Climate Change 1995: The Science of Climate Change - Contribution of Working Group I to the Second Assessment of the Intergovernmental Panel on Climate Change (IPCC). Cambridge, UK, Cambridge University Press.

UNFCCC, 2015. Historic Paris Agreement on Climate Change 195 Nations Set Path to Keep Temperature Rise Well Below 2 Degrees Celsius.

Vauhkonen, J., Packalen, T., 2018. Uncertainties related to climate change and forest management with implications on climate regulation in Finland. Ecosyst. Serv. 33, 213-224. https://doi.org/10.1016/ j.ecoser.2018.02.011.

Yan, Q., Yin, J., Baležentis, T., Makutenienė, D., Štreimikienė, D., 2017. Energy-related GHG emission in agriculture of the European countries: An application of the Generalized Divisia Index. J. Clean. Prod. 164, 686-694. https://doi.org/10.1016/j.jclepro.2017.07.010

Zheng, X., Streimikiene, D., Balezentis, T., Mardani, A., Cavallaro, F., Liao, H., 2019. A review of greenhouse gas emission profiles, dynamics, and climate change mitigation efforts across the key climate change players. J. Clean. Prod. https://doi.org/10.1016/j.jclepro.2019.06.140.

This article is an open access article distributed under the terms and conditions of the Creative Commons Attribution (CC BY-NC-ND 4.0) license (https://creativecommons.org/licenses/by-nc-nd/4.0/). 